\title{
Intracorporeal esophagojejunostomy using a linear stapler in laparoscopic total gastrectomy: comparison with circular stapling technique
}

Sejin Lee ${ }^{1,2}$, Harim Lee ${ }^{1}$, Jeong Ho Song ${ }^{1,2}$, Seohee Choi ${ }^{1,2}$, Minah Cho ${ }^{1,2}$, Taeil Son ${ }^{1,2}$, Hyoung-II Kim ${ }^{1,2}$ and Woo Jin Hyung ${ }^{1,2^{*}}$

\begin{abstract}
Background: Laparoscopic total gastrectomy for gastric cancer is feasible but less commonly performed compared to laparoscopic distal gastrectomy due to technical difficulties such as reconstruction. There is no standard esophagojejunal anastomosis technique in laparoscopic total gastrectomy due to a lack of evidence.

Methods: We retrospectively analyzed data from 213 patients with gastric cancer who underwent laparoscopic total gastrectomy from October 2012 to December 2016. Of these, 109 and 104 patients underwent esophagojejunostomy with linear and circular stapling, respectively. We compared short-term postoperative outcomes, including surgical complications and anastomosis costs between both groups.

Results: The mean operation time in the linear stapler group was longer than the circular stapler group (Linear stapler, $235.3 \pm 57.9$ vs. Circular stapler, $217.1 \pm 55.8 \mathrm{~min} ; P=0.021$ ); however, D2 lymph node dissection was performed more in the linear stapler group (Linear stapler, 36.7\% vs. Circular stapler, 23.1\%; $P=0.030$ ). There were two anastomosis leakages in each group (Linear stapler, 1.8\% vs. Circular stapler, 1.9\%; $P>0.999$ ). Anastomosis stenosis only occurred in the circular stapler group (Linear stapler, $0 \%$ vs. Circular stapler, $7.7 \% ; P=0.003$ ). Although the linear stapling technique used more stapler cartridges (Linear stapler, $7.6 \pm 1.1$ vs. Circular stapler, 4.8 $\pm 0.9 ; P<$ 0.001 ), costs related to anastomosis were lower in the linear stapler group (Linear stapler, 1,904,679 $\pm 342,116$ vs. Circular stapler, 2,246,150 $\pm 427,136 \mathrm{KRW} ; P<0.001$ ).

Conclusions: Esophagojejunostomy with the linear stapling technique reduces anastomosis stenosis in laparoscopic total gastrectomy. It can be recommended as a safe and more cost-effective method for esophagojejunal anastomosis.
\end{abstract}

Keywords: Laparoscopic total gastrectomy, Esophagojejunostomy, Linear stapler, Circular stapler, Stenosis

\footnotetext{
* Correspondence: wjhyung@yuhs.ac

'Department of Surgery, Yonsei University College of Medicine, 50-1

Yonsei-ro Seodaemun-gu, Seoul 03722, Republic of Korea

${ }^{2}$ Gastric Cancer Center, Yonsei Cancer Center, Yonsei University Health

System, Seoul, Republic of Korea
}

(c) The Author(s). 2020 Open Access This article is licensed under a Creative Commons Attribution 4.0 International License, which permits use, sharing, adaptation, distribution and reproduction in any medium or format, as long as you give appropriate credit to the original author(s) and the source, provide a link to the Creative Commons licence, and indicate if changes were made. The images or other third party material in this article are included in the article's Creative Commons licence, unless indicated otherwise in a credit line to the material. If material is not included in the article's Creative Commons licence and your intended use is not permitted by statutory regulation or exceeds the permitted use, you will need to obtain permission directly from the copyright holder. To view a copy of this licence, visit http://creativecommons.org/licenses/by/4.0/ The Creative Commons Public Domain Dedication waiver (http://creativecommons.org/publicdomain/zero/1.0/) applies to the data made available in this article, unless otherwise stated in a credit line to the data. 


\section{Background}

Laparoscopic surgery for gastric cancer has become a preferred treatment option with its minimally invasive nature and benefits of short-term surgical outcomes [1]. For distal gastrectomy, ample evidence supports the technical and oncological safety of the laparoscopic approach [2-4]. Conversely, laparoscopic total gastrectomy is not commonly performed due to its technical difficulties, although the procedure is technically feasible [5-8]. Difficulties associated with esophagojejunal anastomosis and lymph node dissection along the splenic vessels are the major barriers to laparoscopy for total gastrectomy. Esophagojejunal anastomosis is closely related to surgical safety, whereas lymph node dissection is a matter of oncologic safety. The technical difficulties of esophagojejunal anastomosis make surgeons more reluctant to perform laparoscopic total gastrectomy.

Several esophagojejunal anastomosis techniques have been introduced, improving the positive initial experience for laparoscopic total gastrectomy. Initially, a circular stapling technique for esophagojejunostomy was widely employed in laparoscopic total gastrectomy since surgeons were familiar with its use during open total gastrectomy $[9,10]$. The linear stapling technique was introduced more recently $[11,12]$. There is no standard esophagojejunal anastomosis technique for laparoscopic total gastrectomy because only a few studies have compared laparoscopic esophagojejunostomy techniques [13-15]. Moreover, no study has compared costeffectiveness between the linear and circular stapling techniques for esophagojejunostomy in laparoscopic total gastrectomy. We aimed to identify the optimal method by comparing postoperative outcomes, including surgical complications and cost for esophagojejunostomy for the linear and circular stapling techniques.

\section{Methods \\ Patients}

We retrospectively reviewed a prospective database of patients with gastric cancer who underwent laparoscopic total gastrectomy between October 2012 and December 2016. This study was approved by the Institutional Review Board of Severance Hospital, Yonsei University Health System (4-2016-0771), which waived the need for informed consent for the use of patient data due to the retrospective nature of the study.

A total of 213 consecutive patients underwent laparoscopic total gastrectomy with Roux-en-Y esophagojejunostomy for gastric cancer during the study period. All patients were diagnosed and evaluated preoperatively by upper endoscopy and abdominal-pelvic computed tomography. Of these, 109 and 104 patients underwent esophagojejunostomy with the linear and circular stapling technique, respectively. We collected preoperative information including age, sex, body mass index (BMI), and American Society of Anesthesiologists Physical Status from our database. We evaluated the pathological stage based on the 8th edition of the American Joint Committee on Cancer staging system.

\section{Surgical procedure}

Surgical procedures were performed by four surgeons, who were experts with more than 200 cases of laparoscopic gastrectomy with over 3 years of experience. The anastomosis technique was determined by surgeons' preference. Detailed procedures for stomach mobilization and lymph node dissection during laparoscopic total gastrectomy at our institution have been described previously [16].

\section{Esophagojejunostomy with using the linear stapler}

The exposed esophagus was adequately mobilized and rotated 90 degrees in a counter-clockwise direction to transect it from the anterior to the posterior wall. The esophagus was partially $(2 / 3$ or $4 / 3)$ transected using a linear stapler (Fig. 1a). The spared esophagus was completely transected using an ultrasonic device, leaving a small entry hole (Fig. 1b). The proximal jejunum, approximately $20-30 \mathrm{~cm}$ from the Treitz ligament, which is a tension-free area for anastomosis, was brought to the transected esophagus. Then, the posterior wall of the esophagus and anti-mesenteric side of the jejunum were anastomosed intracorporeally using the overlap method with a linear stapler (Fig. 1c). The common entry hole was usually closed with a linear stapler (Fig. 1d), although we occasionally performed hand-sewn closure when the anastomosis was high in the mediastinum. The biliary limb of the jejunal loop, located $2-3 \mathrm{~cm}$ proximal to the anastomosis, was divided without mesenteric division (Fig. 1e). Small holes were created at the antimesenteric borders of the biliary limb and the Roux limb at $50 \mathrm{~cm}$ distal to the esophagojejunostomy, and two loops were approximated intracorporeally by the linear stapler (Fig. 1f). The common entry hole for the jejunojunostomy was closed with a linear stapler.

\section{Esophagojejunostomy using the circular stapler}

After mobilization of the entire stomach, two laparoscopic bulldog clamps were applied on the distal esophagus using a vascular clip applicator through the right lower port (Fig. 2a). Then the esophagus was transected with an ultrasonic device (Fig. 2b). A full-layer pursestring suture was applied using non-absorbable 2-0 thickness monofilament materials (Fig. 2c). After completing the purse-string suture, the resected stomach was taken out through a 4- to 5-cm mini-laparotomy at the left lower trocar port site on the left flank. The jejunum was brought out, and a jejunojejunostomy was 

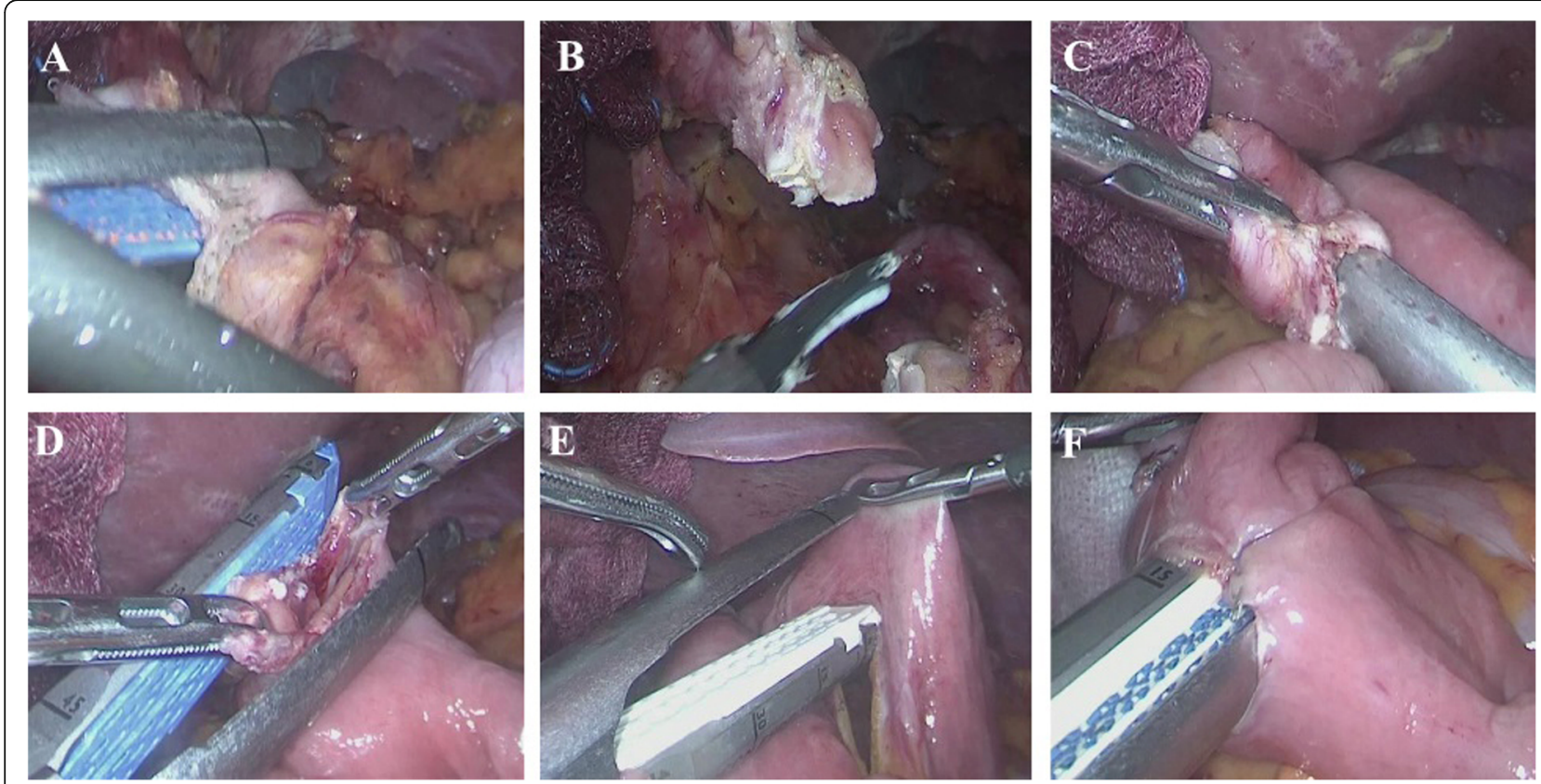

Fig. 1 Esophagojejunostomy using the linear stapling technique. a Partial transection of the esophagus using a linear stapler. b Complete transection of the esophagus using an ultrasonic device. c Intracoporeal anastomosis using the overlap method. $\mathbf{d}$ Closure of the entry hole. $\mathbf{e}$ Jejunum transection without mesenteric division using a linear stapler. $\mathbf{f}$ Jejunojejunostomy $50 \mathrm{~cm}$ distal to the esophagojejunostomy
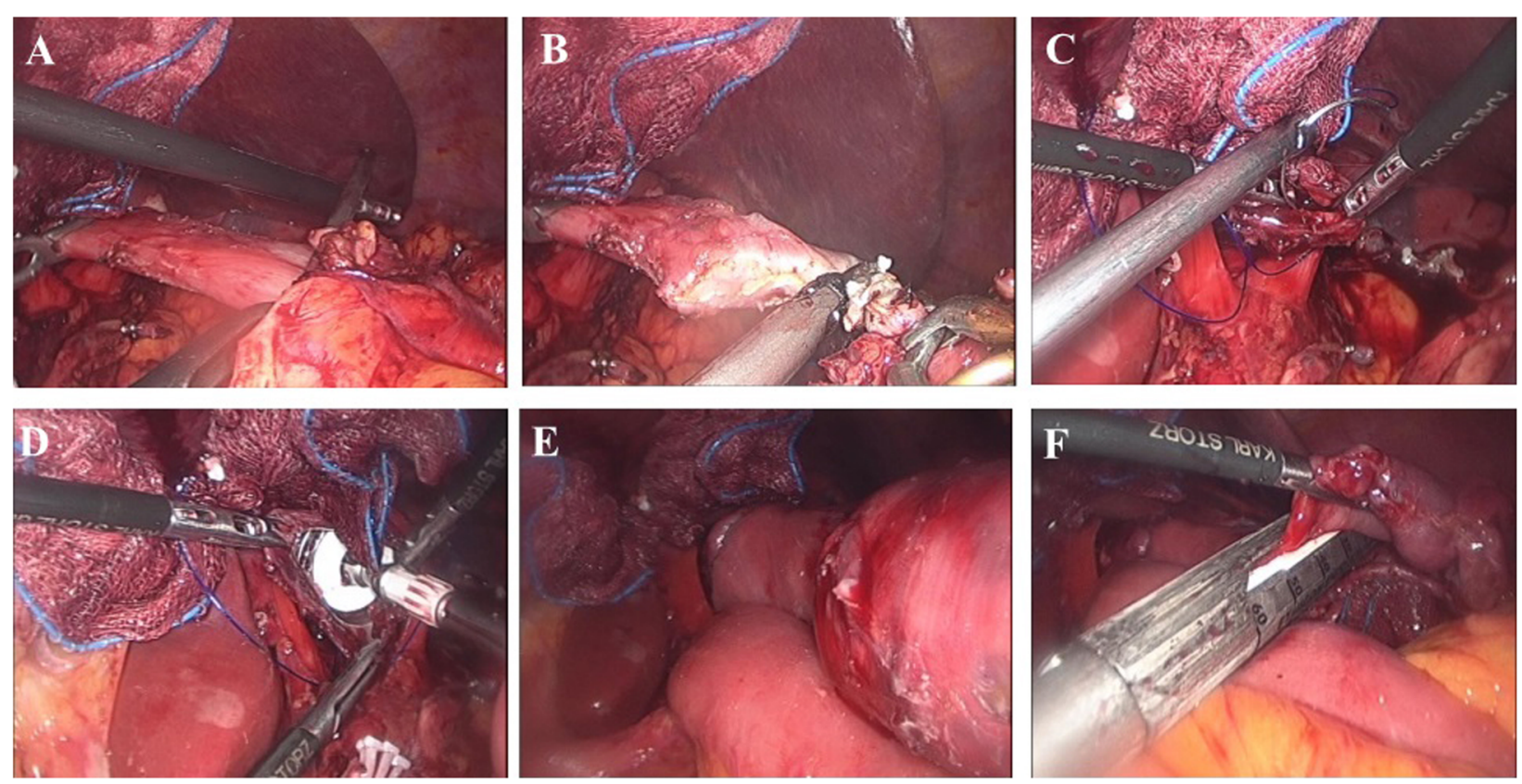

Fig. 2 Esophagojejunostomy using the circular stapling technique. a Application of two laparoscopic bulldog clamps. b Transection of the esophagus using an ultrasonic device. c Purse-string suture. $\mathbf{d}$ Introduction of an anvil into the esophagus. e Approximation of the circular stapler. f Jejunal stump closure 
made extracorporeally by the linear stapler to create a side-to-side anastomosis at $50 \mathrm{~cm}$ distal to the esophagojejunostomy. The common entry hole for the jejunojunostomy was closed by hand-sewn or linear stapler. The anvil and circular stapler body inserted in the jejunum were introduced into the peritoneal cavity. A surgical glove with a wound protector covered the minilaparotomy to maintain the pneumoperitoneum. The anvil was introduced into the esophagus (Fig. 2d), and the previously made purse-string suture was tied. The anvil and circular stapler body were approximated (Fig. $2 \mathrm{e})$, the esophagojejunostomy was completed, and the jejunal stump was closed with a linear stapler (Fig. 2).

\section{Surgical outcomes, complications, and cost}

We retrieved all the surgery-related variables and postoperative recovery data, including surgical outcomes and complications from our prospectively collected database. We analyzed operative time, estimated blood loss, combined resection, and extent of lymph node dissection. Time to first flatus and oral intake and postoperative hospital stay were also analyzed to assess postoperative recovery. We graded postoperative complications according to the Clavian-Dindo classification [17]. For postoperative complications, especially for evaluating anastomosis-related complications, we assessed all postoperative endoscopy and abdominal-pelvic computed tomography results for more than 2 years after surgery. We defined patients with anastomotic stenosis as treated with balloon dilatation or detected under endoscopy without dilatation. We calculated anastomosis-related costs with stapling supplies and extra supplies for all the anastomoses. The stapling supplies included the costs of the circular stapler and liner stapler body and cartridges, while the extra supplies included the costs of wound protector and suture materials.

\section{Statistical analysis}

Statistical analyses were performed with IBM SPSS Statistics software for Windows, version 23.0 program (Armonk, NY: IBM Corp.). All data are expressed as mean \pm standard deviation. Categorical variables were analyzed with chi-square and Fisher's exact tests, and continuous variables were analyzed using Student's $t$ test. $P<0.05$ was considered statistically significant.

\section{Results}

\section{Clinicopathological features (Table 1)}

The linear and circular stapler groups consisted of 109 and 104 patients, and their mean ages were $60.0 \pm 12.0$ and $58.7 \pm 12.5$ years, respectively $(P=0.440)$. In the linear stapler group, $63(57.8 \%)$ patients were male compared to $72(69.2 \%)$ in the circular stapler group $(P=$ 0.083). The mean BMI in the linear stapler group was
Table 1 Clinicopathologic features

\begin{tabular}{llll}
\hline & $\begin{array}{l}\text { Linear } \\
(n=109)\end{array}$ & $\begin{array}{l}\text { Circular } \\
(n=104)\end{array}$ & $p$-value \\
\hline Age (year) & $60.0 \pm 12.0$ & $58.7 \pm 12.5$ & 0.440 \\
Sex & & & 0.083 \\
$\quad$ Male & $63(57.8 \%)$ & $72(69.2 \%)$ & \\
$\quad$ Female & $46(42.2 \%)$ & $32(30.8 \%)$ & \\
BMI (kg/m $\left.{ }^{2}\right)$ & $23.5 \pm 3.1$ & $23.4 \pm 2.6$ & 0.687 \\
ASA classification & & & 0.108 \\
I & $17(15.6 \%)$ & $27(26.0 \%)$ & \\
II & $63(57.8 \%)$ & $58(55.8 \%)$ & \\
III/IV & $29(26.6 \%)$ & $19(18.3 \%)$ & \\
pT stage & & & \\
T1 & $73(67.0 \%)$ & $71(68.3 \%)$ & \\
T2 & $10(9.2 \%)$ & $16(15.4 \%)$ & \\
T3 & $16(14.7 \%)$ & $6(5.8 \%)$ & \\
T4 & $10(9.2 \%)$ & $11(10.6 \%)$ & \\
pN stage & & & \\
N0 & $85(78.0 \%)$ & $94(90.4 \%)$ & \\
N(+) & $24(22.0 \%)$ & $10(9.6 \%)$ & \\
\hline ASA Amein) & & \\
\hline
\end{tabular}

ASA American Society of Anesthesiologists, BMI body mass index

$23.5 \pm 3.1 \mathrm{~kg} / \mathrm{m}^{2}$ compared to $23.4 \pm 2.6 \mathrm{~kg} / \mathrm{m}^{2}$ in the circular stapler group $(P=0.687)$. There was no significant difference in the proportion of pathologic depth of invasion $(P=0.117)$. However, there were more patients with lymph node metastasis in the linear stapler group compared with the circular stapler group (22.0 vs. $9.6 \%$, $P=0.013)$.

Table 2 Operative outcomes and postoperative recovery

\begin{tabular}{llll}
\hline & $\begin{array}{l}\text { Linear } \\
(n=109)\end{array}$ & $\begin{array}{l}\text { Circular } \\
(n=104)\end{array}$ & $p$-value \\
\hline Operative time (min) & $235.3 \pm 57.9$ & $217.1 \pm 55.8$ & 0.021 \\
Estimated blood loss (ml) & $135.7 \pm 156.1$ & $106.6 \pm 95.1$ & 0.104 \\
Combined resection & & & 0.323 \\
$\quad$ None & $99(90.8 \%)$ & $90(86.5 \%)$ & \\
Done & $10(9.2 \%)$ & $14(13.5 \%)$ & \\
Extent of lymph node dissection & & & 0.030 \\
D1 + & $69(63.3 \%)$ & $80(76.9 \%)$ & \\
D2 & $40(36.7 \%)$ & $24(23.1 \%)$ & \\
Postoperative recovery & & & \\
Flatus (days) & $3.3 \pm 1.3$ & $3.6 \pm 1.0$ & 0.053 \\
SOW (days) & $2.2 \pm 0.5$ & $3.7 \pm 2.6$ & $<0.001$ \\
Soft diet (days) & $4.3 \pm 2.8$ & $5.0 \pm 2.8$ & 0.073 \\
LOS (days) & $7.4 \pm 5.2$ & $7.8 \pm 5.4$ & 0.553 \\
\hline
\end{tabular}

LOS length of hospital stay, SOW sips of water 
Operative outcomes and postoperative recovery (Table 2) The mean operation time in the linear stapler group was longer than the circular stapler group (linear stapler, $235.3 \pm 57.9$ vs. circular stapler, $217.1 \pm 55.8 \mathrm{~min} ; P=$ 0.021). There was no significant difference between the two groups in mean estimated blood loss $(P=0.104)$ or the rate of combined resection $(P=0.323)$. However, D2 lymph node dissection was performed more often in the linear stapler group compared with the circular stapler group (linear stapler, $36.7 \%$ vs. circular stapler, $23.1 \%$; $P=0.030)$.

Time to first flatus was earlier in the linear stapler group, although it was not statistically different $(P=0.053)$. Time to first water intake was significantly earlier in the linear stapler group (linear stapler, $2.2 \pm 0.5$ vs. circular stapler, $3.7 \pm 2.6$ days; $P<0.001$ ); however, time to first semi-solid diet did not differ between the two groups $(P=0.073)$. The postoperative hospital stay length was not significantly different between the two groups $(P=0.553)$.

\section{Postoperative complications (Table 3)}

Patients with postoperative complications, including major and minor complications, were 74 (67.9\%) in the linear stapler group and 69 (66.3\%) in the circular stapler group $(P=0.811)$. Most complications were grade I and II, including fever, wound complication, transfusion, delirium, voiding difficulty, postoperative ileus, and use of pancreas- or liver-supporting medications or antibiotics.

Table 3 Postoperative complications

\begin{tabular}{llll}
\hline & $\begin{array}{l}\text { Linear } \\
(n=109)\end{array}$ & $\begin{array}{l}\text { Circular } \\
(n=104)\end{array}$ & $p$-value \\
\hline Absent & $35(32.1 \%)$ & $35(33.7 \%)$ & 0.811 \\
Present & $74(67.9 \%)$ & $69(66.3 \%)$ & \\
Complication gradea & & & 0.112 \\
I & $37(50.0 \%)$ & $33(47.8 \%)$ & \\
II & $29(39.2 \%)$ & $20(29.0 \%)$ & \\
$\geq$ III & $8(10.8 \%)$ & $16(23.2 \%)$ & \\
Type of early complications (0-30d) & & & \\
Anastomotic leakage & 2 & 2 & $>0.999$ \\
Duodenal stump leakage & 1 & 0 & 0.512 \\
Intraluminal bleeding & 1 & 0 & 0.512 \\
Intra-abdominal fluid collection & 3 & 3 & 0.636 \\
Postoperative obstruction & 1 & 1 & 0.739 \\
Pulmonary complication & 3 & 4 & 0.474 \\
Type of late complications (>30d) & 3 & 4 & 0.474 \\
Anastomotic stenosis & 0 & 8 & 0.003 \\
Postoperative obstruction & 6 & 5 & 0.818 \\
Hiatal hernia & 2 & 0 & 0.498 \\
\hline
\end{tabular}

a Complication grade was determined according to the Clavian-Dindo classification of surgical complications
The rate of complications grade III or higher was $10.8 \%$ in the linear stapler group and $23.2 \%$ in the circular stapler group. In the linear stapler group, there were 7 (6.2\%) patients with grade III complications and 1 $(0.9 \%)$ with a grade V complication $(0.9 \%)$. The grade III complications were pleural effusion $(n=1)$, intraabdominal fluid collection $(\mathrm{n}=1)$, and postoperative obstruction $(n=5)$, while the grade $\mathrm{V}$ complication was an anastomotic leakage at the esophagojejunostomy. In the circular stapler group, there were $11(10.6 \%)$ patients with grade III complications, $4(3.8 \%)$ with grade IV complications, and $1(1.0 \%)$ with a grade $\mathrm{V}$ complication. The grade III complications were an intra-abdominal fluid collection $(n=1)$, duodenal stump leakage $(n=1)$, postoperative obstruction $(n=3)$, anastomotic leakages $(n=2)$, and anastomotic stenosis $(n=4)$; grade IV complications were pulmonary complications $(n=3)$ and postoperative bleeding $(n=1)$; and the grade V complication was postoperative bleeding.

Early complications were defined as an adverse event occurring within 30 days after surgery. Among early complications, there were $2(1.8 \%)$ esophagojejunostomy leakages in the linear stapler group and $2(1.9 \%)$ in the circular stapler group. All anastomotic stenosis occurred over 30 days after surgery, which regarded as a late complication in the circular stapler group (linear stapler, $0 \%$ vs. circular stapler, $7.7 \%, P=0.003$ ). Of these patients with anastomotic stenosis, there were 4 patients with grade III complications treated with balloon dilatation, and others had difficulty passing the endoscope, but no symptoms.

\section{Anastomosis-related cost (Table 4)}

Total anastomosis-related cost was lower in the linear stapler group compared with the circular stapler group (linear stapler, $1,904,679 \pm 342,116$ vs. circular stapler, 2,250,481 $\pm 430,440 \mathrm{KRW}, P<0.001$ ). Because the linear stapling technique used more linear stapler cartridges (linear stapler, $7.6 \pm 1.1$ vs. circular stapler, $4.8 \pm 0.9, P<0.001)$, the cost of linear stapler was higher (linear stapler, $1,871,927 \pm 321,200$ vs. circular stapler, 1,651,154 $\pm 429,688 \mathrm{KRW} P<0.001$ ). However, in the circular stapler group, there were the additional cost of the circular stapler $(470,000 \mathrm{KWR})$ and higher extra supply costs compared with the linear stapler group (linear stapler, 32,752 $\pm 52,013$ vs. circular stapler, 130,000 KRW; $P<0.001$ ).

\section{Discussion}

In this study, the rates of anastomosis leakage were similar between the two groups, but stenosis of the esophagojejunostomy anastomosis was less frequent with the linear stapling technique. Furthermore, the linear 
Table 4 Anastomosis-related cost

\begin{tabular}{|c|c|c|c|}
\hline & $\begin{array}{l}\text { Linear } \\
(n=109)\end{array}$ & $\begin{array}{l}\text { Circular } \\
(n=104)\end{array}$ & $p$-value \\
\hline Total cost ${ }^{a}$ (Range) & $1,904,679 \pm 342,116(1,450,000-3,410,000)$ & $2,251,154 \pm 429,688(1,660,000-3,800,000)$ & $<0.001$ \\
\hline Stapling supplies cost ${ }^{a}$ & $1,871,927 \pm 321,200$ & $2,121,154 \pm 429,688$ & $<0.001$ \\
\hline Circular stapler & 0 & 470,000 & \\
\hline Linear stapler & $1,871,927 \pm 321,200$ & $1,651,154 \pm 429,688$ & $<0.001$ \\
\hline Number of linear stapler cartridges & $7.6 \pm 1.1$ & $4.8 \pm 0.9$ & $<0.001$ \\
\hline Extra supplies cost ${ }^{\mathrm{ab}}$ & $32,752 \pm 52,013$ & 130,000 & $<0.001$ \\
\hline
\end{tabular}

a In Korean won

${ }^{b}$ Extra supplies costs included the wound protector and suture materials

stapling technique had a lower total cost for anastomosis, despite the need for more linear stapler cartridges.

Fewer stenoses in the linear stapling group were probably related to the creation of a wide lumen $(>30 \mathrm{~mm}$ diameter) when using 45-mm linear staplers [18]. In addition, there was less wound retraction due to an everted anastomosis at the entry hole for the linear stapling technique, resulting in less stenosis [19]. Previous studies of the linear stapling technique for the esophagojejunostomy in laparoscopic total gastrectomy also reported reductions in anastomotic stenosis compared to the circular stapling technique $[20,21]$.

There is no standardized assessment for esophagojejunostomy stenosis after total gastrectomy. Moreover, it is difficult to include patients who have subjective stenosis symptoms without endoscopic evidence of stenosis. Therefore, we included patients with stenosis both treated with balloon dilatation and detected under endoscopy without dilatation to avoid underestimating the incidence of stenosis.

Unlike anastomotic stenosis, there was no difference in the incidences of anastomotic leakage in our study. Previous comparative studies reported lower incidences of anastomotic leakage for the linear stapler group than the circular stapler group [14, 15]. Several factors could influence the low rate of anastomotic leakage for the linear stapling technique. It might reduce technical errors by providing a better view of the surgical field than the circular stapling technique [22]. Three rows with the linear stapler would produce a more watertight anastomosis than two rows using the circular stapler [23].

Our rates of anastomotic leakage were quite low for both stapling techniques compared to other studies [14, 15]. Similar rates are probably because we performed the same operative procedure in both groups except for using different stapler types. We preserved the jejunal vascular arcade to maintain the bidirectional arterial supply and venous drainage to prevent the ischemia and congestion at the anastomosis site, since inadequate blood supply and venous drainage are important causes of anastomotic leakage. Compared with the circular stapler, the linear stapling technique may not reduce anastomotic leakage at the esophagojejunostomy in laparoscopic total gastrectomy, provided that adequate blood supply and venous drainage at the anastomosis site are maintained.

In this study, we compared the costs of anastomosis based on the assumption that it would be more expensive to use the linear stapling technique, which uses more cartridges. Assuming the other processes are the same, the linear stapling technique during esophagojejunostomy uses two additional linear stapler cartridges than the circular stapling technique that uses a circular stapler. The cost of linear stapler cartridges varied by company (45-mm cartridge: 290,000 vs 180,000 won, 60 mm cartridge: 400,000 vs. 210,000 won, respectively). Since we typically used a $45-\mathrm{mm}$ linear stapler, the price of two linear stapler cartridges is lower than that of a circular stapler (470,000 won), which requires a wound protector (130,000 won). Moreover, anastomosis cost with the linear stapling technique could be reduced if entry hole closure is done by laparoscopic suture. Therefore, the linear stapling technique is a cost-efficient anastomosis option for the esophagojejunostomy in laparoscopic total gastrectomy.

Although surgeons are familiar with using a circular stapler for esophagojejunostomy, performing this procedure laparoscopically introduces several technical complexities. In a limited laparoscopic view, it is difficult to make purse-string sutures, indwell the anvil into the esophagus, and manipulate the circular stapler [24]. In addition, a mini-laparotomy is necessary to access the esophagus during circular stapling. Mini-laparotomy is not necessary for the linear stapling technique, which conducts intracorporeal anastomosis. The linear stapler is also more comfortable to handle in a limited operative field [25]. Moreover, it can be used in patients with narrow esophagus. Based on our results, the linear stapling technique is a better esophagojejunal anastomosis method than the circular stapling technique. 
Our study is limited in that we only assessed Asian patients. It is unclear if the circular stapling technique would be associated with anastomotic stenosis in Western patients who have relatively wider esophageal lumens. In our results, there were only eight patients with a $B M I \geq 25 \mathrm{~kg} / \mathrm{m}^{2}$, so our findings might not be generalizable to high BMI patients that are more frequent in Western countries than Asians. From a surgical perspective, overweight patients have a higher risk of postoperative complications due to comorbidities. The surgeon's preference in the esophagojejunostomy method and differences in the linear stapler cartridge length and stapler manufacturers are additional limitations. A well-designed randomized controlled trial with a large, heterogeneous cohort is required to identify the optimal anastomosis method for esophagojejunostomy in laparoscopic total gastrectomy.

\section{Conclusion}

In laparoscopic total gastrectomy, esophagojejunostomy by the linear stapling technique can reduce anastomosis stenosis compared to the circular stapling technique. Linear stapling can be recommended as a safe and more cost-effective option for esophagojejunal anastomosis.

\section{Abbreviations}

BMI: Body mass index; ASA: American Society of Anesthesiologists; LOS: Length of hospital stay; SOW: Sips of water

\section{Acknowledgments}

Not applicable.

\section{Authors' contributions}

SL contributed to the design of the study, acquisition, analysis, and interpretation of data, and drafting the manuscript. $\mathrm{HL}$ contributed to the acquisition, analysis, and interpretation of the data. JHS, SC, and MC assisted in drafting the manuscript. TS, HK performed operations and gave critical reviews of the manuscript. WJH contributed to the design of the study, involved in drafting and reviewing the manuscript and gave final approval to be published. All authors read and approved the final manuscript.

\section{Funding}

None.

\section{Availability of data and materials}

The data that support the conclusion of this study are available from the corresponding author upon reasonable request.

\section{Ethics approval and consent to participate}

This study was approved by the Institutional Review Board of Severance Hospital, Yonsei University Health System (4-2016-0771), which waived the need for informed consent for the use of patient data due to the retrospective nature of the study.

\section{Consent for publication}

Not applicable.

\section{Competing interests}

Dr. Woo Jin Hyung has stock in Hutom, received research grants from Medtronic and GC Pharma, and is a consultant for Ethicon and Verb Surgical. Sejin Lee, Harim Lee, Jeong Ho Song, Seohee Choi, Minah Cho, Taeil Son, and Hyoung-\| Kim have no conflicts of interest or financial ties to disclose.
Received: 23 September 2019 Accepted: 15 April 2020

Published online: 12 May 2020

\section{References}

1. Guideline Committee of the Korean Gastric Cancer Association DWG, Review P. Korean practice guideline for gastric Cancer 2018: an evidencebased, multi-disciplinary approach. J Gastric Cancer. 2019;19(1):1-48. https:// doi.org/10.5230/jgc.2019.19.e8.

2. Kim W, Kim HH, Han SU, Kim MC, Hyung WJ, Ryu SW, et al. Decreased morbidity of laparoscopic distal gastrectomy compared with open distal Gastrectomy for stage I gastric cancer: short-term outcomes from a multicenter randomized controlled trial (KLASS-01). Ann Surg. 2016;263(1): 28-35. https://doi.org/10.1097/SLA.0000000000001346.

3. Katai H, Mizusawa J, Katayama H, Takagi M, Yoshikawa T, Fukagawa T, et al. Short-term surgical outcomes from a phase III study of laparoscopy-assisted versus open distal gastrectomy with nodal dissection for clinical stage IA/IB gastric cancer: Japan clinical oncology group study JCOG0912. Gastric Cancer. 2017;20(4):699-708. https://doi.org/10.1007/s10120-016-0646-9.

4. Lee HJ, Hyung WJ, Yang HK, Han SU, Park YK, An JY, et al. Short-term outcomes of a multicenter randomized controlled trial comparing laparoscopic distal Gastrectomy with D2 lymphadenectomy to open distal Gastrectomy for locally advanced gastric cancer (KLASS-02-RCT). Ann Surg. 2019. https://doi.org/10.1097/SLA.0000000000003217.

5. Topal B, Leys E, Ectors N, Aerts R, Penninckx F. Determinants of complications and adequacy of surgical resection in laparoscopic versus open total gastrectomy for adenocarcinoma. Surg Endosc. 2008;22(4):980-4 https://doi.org/10.1007/s00464-007-9549-5.

6. Moisan F, Norero E, Slako M, Varas J, Palominos G, Crovari F, et al. Completely laparoscopic versus open gastrectomy for early and advanced gastric cancer: a matched cohort study. Surg Endosc. 2012;26(3):661-72. https://doi.org/10.1007/s00464-011-1933-5.

7. Kim HS, Kim BS, Lee IS, Lee S, Yook JH, Kim BS. Comparison of totally laparoscopic total gastrectomy and open total gastrectomy for gastric cancer. J Laparoendosc Adv Surg Tech A. 2013;23(4):323-31. https://doi.org/ 10.1089/lap.2012.0389.

8. Hyung WJ, Yang HK, Han SU, Lee YJ, Park JM, Kim JJ, et al. A feasibility study of laparoscopic total gastrectomy for clinical stage I gastric cancer: a prospective multi-center phase II clinical trial, KLASS 03. Gastric Cancer. 2019;22(1):214-22. https://doi.org/10.1007/s10120-018-0864-4.

9. Dulucq JL, Wintringer P, Perissat J, Mahajna A. Completely laparoscopic total and partial gastrectomy for benign and malignant diseases: a single institute's prospective analysis. J Am Coll Surg. 2005;200(2):191-7. https:// doi.org/10.1016/j.jamcollsurg.2004.10.004.

10. Usui S, Nagai K, Hiranuma S, Takiguchi N, Matsumoto A, Sanada K. Laparoscopy-assisted esophagoenteral anastomosis using endoscopic purse-string suture instrument "Endo-PSI (II)" and circular stapler. Gastric Cancer. 2008;11(4):233-7. https://doi.org/10.1007/s10120-008-0481-8.

11. Okabe H, Obama K, Tanaka E, Nomura A, Kawamura J, Nagayama S, et al. Intracorporeal esophagojejunal anastomosis after laparoscopic total gastrectomy for patients with gastric cancer. Surg Endosc. 2009;23(9):216771. https://doi.org/10.1007/s00464-008-9987-8.

12. Inaba K, Satoh S, Ishida Y, Taniguchi K, Isogaki J, Kanaya S, et al. Overlap method: novel intracorporeal esophagojejunostomy after laparoscopic total gastrectomy. J Am Coll Surg. 2010;211(6):e25-9. https://doi.org/10.1016/j. jamcollsurg.2010.09.005.

13. Kim EY, Choi HJ, Cho JB, Lee J. Totally laparoscopic total gastrectomy versus laparoscopically assisted Total Gastrectomy for gastric cancer. Anticancer Res. 2016;36(4):1999-2003.

14. Gong CS, Kim BS, Kim HS. Comparison of totally laparoscopic total gastrectomy using an endoscopic linear stapler with laparoscopic-assisted total gastrectomy using a circular stapler in patients with gastric cancer: a single-center experience. World J Gastroenterol. 2017;23(48):8553-61. https://doi.org/10.3748/wjg.v23.i48.8553.

15. Kyogoku N, Ebihara Y, Shichinohe T, Nakamura F, Murakawa K, Morita T, et al. Circular versus linear stapling in esophagojejunostomy after laparoscopic total gastrectomy for gastric cancer: a propensity scorematched study. Langenbeck's Arch Surg. 2018;403(4):463-71. https://doi.org/ 10.1007/s00423-018-1678-x

16. Hyung WJ, Lim JS, Song J, Choi SH, Noh SH. Laparoscopic spleen-preserving splenic hilar lymph node dissection during total gastrectomy for gastric 
cancer. J Am Coll Surg. 2008;207(2):e6-11. https://doi.org/10.1016/j. jamcollsurg.2008.04.027.

17. Dindo D, Demartines N, Clavien PA. Classification of surgical complications: a new proposal with evaluation in a cohort of 6336 patients and results of a survey. Ann Surg. 2004;240(2):205-13. https://doi.org/10.1097/01.sla. 0000133083.54934.ae.

18. Okabe H, Obama K, Tsunoda S, Tanaka E, Sakai Y. Advantage of completely laparoscopic gastrectomy with linear stapled reconstruction: a long-term follow-up study. Ann Surg. 2014;259(1):109-16. https://doi.org/10.1097/SLA. 0b013e31828dfa5d.

19. Kawakami K, Yamaguchi K, Kishikawa H, Nakayama F. Modes of biliobiliary anastomosis in relation to the healing process and occurrence of postoperative stricture. Surg Today. 1993;23(1):51-7.

20. Umemura A, Koeda K, Sasaki A, Fujiwara H, Kimura Y, Iwaya T, et al. Totally laparoscopic total gastrectomy for gastric cancer: literature review and comparison of the procedure of esophagojejunostomy. Asian J Surg. 2015; 38(2):102-12. https://doi.org/10.1016/j.asjsur.2014.09.006.

21. Inokuchi M, Otsuki S, Fujimori Y, Sato Y, Nakagawa M, Kojima K. Systematic review of anastomotic complications of esophagojejunostomy after laparoscopic total gastrectomy. World J Gastroenterol. 2015;21 (32):9656-65. https://doi.org/10.3748/wjg.v21.i32.9656.

22. Kim HS, Kim BS, Lee S, Lee IS, Yook JH, Kim BS. Reconstruction of esophagojejunostomies using endoscopic linear staplers in totally laparoscopic total gastrectomy: report of 139 cases in a large-volume center. Surg Laparosc Endosc Percutan Tech. 2013;23(6):e209-16. https://doi. org/10.1097/SLE.0b013e31828e3b79.

23. Huang $C, X u X$, Zhuang B, Chen W, Xu X, Wang C, et al. A comparison of cervical delta-shaped anastomosis and circular stapled anastomosis after esophagectomy. World J Surg Oncol. 2017;15(1):31. https://doi.org/10.1186/ s12957-017-1097-4.

24. Okabe H, Tsunoda S, Tanaka E, Hisamori S, Kawada H, Sakai Y. Is laparoscopic total gastrectomy a safe operation? A review of various anastomotic techniques and their outcomes. Surg Today. 2015;45(5):549-58. https://doi.org/10.1007/s00595-014-0901-9.

25. Kim JJ, Song KY, Chin HM, Kim W, Jeon HM, Park CH, et al. Totally laparoscopic gastrectomy with various types of intracorporeal anastomosis using laparoscopic linear staplers: preliminary experience. Surg Endosc 2008;22(2):436-42. https://doi.org/10.1007/s00464-007-9446-y.

\section{Publisher's Note}

Springer Nature remains neutral with regard to jurisdictional claims in published maps and institutional affiliations.

Ready to submit your research? Choose BMC and benefit from:

- fast, convenient online submission

- thorough peer review by experienced researchers in your field

- rapid publication on acceptance

- support for research data, including large and complex data types

- gold Open Access which fosters wider collaboration and increased citations

- maximum visibility for your research: over $100 \mathrm{M}$ website views per year

At BMC, research is always in progress.

Learn more biomedcentral.com/submissions 